\title{
Prevalence of Undiagnosed Hypertension among the Hypertensives Living in the City of Boma. Republic Democratic Republic of the Congo
}

\author{
Blaise Makoso Nimi 1,2, François Lepira Bompeka1,Benjamin Longo Mbenza1,4, Roland Vangu Vangu 2,4, Gedeon Longo \\ Longo2,4 Aliocha Nkodila5, Memoria Makoso Nimi2 , Patrick Kayembe Kalambayi6and Jean René M’Buyamba-Kabangu1. \\ 1 Department of Internal Medicine, University of Kinshasa, DRCongo \\ 2 University Kasa Vubu School of Medicine, Boma, DRCongo \\ 3"Lomo Medical" Center, Kinshasa, DRCongo \\ 4Department of Gynecoligy , University of Kinshasa, DRCongo \\ 5« Cité des Aveugles » Medical Center, Kinshasa, DRCongo \\ 6Kinshasa School of Public Health, University of Kinshasa, DRCongo \\ Blaise Makoso, MD University of Kinshasa, PO Box 123 Kin XI
}

\begin{abstract}
\section{Background:}

Undiagnosed and uncontrolled hypertension are responsible for several cardiovascular complications, particularly in countries with limited resources. The objective of this study was to assess the extent of undiagnosed hypertension in the adult hypertensive in Boma.
\end{abstract}

\section{$>$ Methods:}

We conducted a cross-sectional study using the WHO step wise questionnaire, from March 1 to April 15, 2018. The study included all known hypertensive adults and all those who had high blood pressure during the study. The parameters of interest were age, sex, anthropometric measure and behavioral factors. Independent factors associated with undiagnosed hypertension were identified using logistic regression analysis with $p<0.05$ was significant

\section{Results:}

The prevalence of undiagnosed hypertension was 56. 1\%. Only $47.9 \%$ had controlled BP among known hypertensive. Young age $(\mathbf{p}<0.001)$, no FH-HT $(p=$ 0.030), Low SES $(p<0.012)$ have emerged as the main determinant associated with undiagnosed hypertension.

\section{$>$ Conclusion:}

Undiagnosed hypertension was characterized by a high prevalence and suboptimal BP control. Therapeutic lifestyle changes and pharmacological treatment are needed for those hypertensive participants. Keywords: Prevalence, Undiagnosed hypertension, Boma

\section{INTRODUCTION}

Hypertension (HBP) is the most important cardiovascular risk, the prevalence of which $31.1 \%$ of the global population and continues to increase in low resource countries. He is responsible for high morbidity and mortality $[1,2]$.

The Sub-Saharan Africa (SSA), has experienced in hard-related over the past 10 years when already facing transmitted disease such as tuberculosis and Ebola which is added the burden of hypertension [3, 4].

The burden of HBP is all the more serious since a large number of people with HBP remain undiagnosed, the no control of patient already on antihypertensive medication, hence a risk of morbidity and mortality due to the occurrence of cardiovascular events such as stroke and heart disease [5]. HBP is a shadow killer because it remains as asymptomatic in most cases and only reveals itself Durant complications or during routine consultation. Traitment and control depends not only on screening, socio-economic level but also well-established traitment with good quality drugs [6-8]. The undiagnosed HBP prevalence in a population varies from one country to another and seems higher in developing countries such as RDC in which the screening and traitment strategy barely take off. For instance, the prevalence of undiagnosed hypertension appears to be much higher in developing countries [9-13]. If certain studies carries out in provinces of the RDC have found as determinant of HBP , overweight, obesity and transition away from traditional diet, those carried in Central kongo reported, socio demographic factors, such as education, are associated with higher rates of hypertension in populations [14-16]. 
In countries in Sub-Saharan Africa, factors such as poor access to health information and services, and low socio-economic status have been reported to contribute substantially to the high prevalence of undiagnosed hypertension. Regarding socioeconomic status, especially in terms of level of education, and occupation, low level of education, low income and stressful life occupations have been linked with the prevalence of undiagnosed hypertension [3].

In RD Congo, all those studies that have used the WHO steps report a high prevalence of known arterial hypertension as well that unknown in the whole population. Thus, it was necessary to conduct a similar study in the port and cosmopolitan city of Boma in the R.D.Congo [14, 1618]. Given the high prevalence Of hypertension and its complications in the city of Boma, we set ourselves the objective of determining the prevalence of undiagnosed hypertension, of mounting the strategies in order to make adequate decision-making both by the population and by authority.

\section{METHODS}

\section{$>$ Study design}

This was a population-based cross-sectional study involving adult population randomly selected.

\section{Study setting}

The study was conducted in Boma, a port city with a population of 459. 361 inhabitants, located in the province of Kongo Central at about $440 \mathrm{Km}$ southwest of Kinshasa, the Capital City. It has mixed urban and rural communities and comprised of three administrative districts and one rural district.

A multistage sampling strategy was used. The city of Boma includes 3 urban districts and 1 rural district. In all these districts, the lists of existing streets were obtained and 2 streets were selected in each district using simple random sampling strategy. On the streets drawn all the inhabited plots were listed in order to constitute the sampling frame. All the parcels listed with the odd numbers have been selected. In the selected plots, all residents aged 18 or over were invited to participate in the study.

We included 1178 households in which 3510 adults consented and were examined. We retained 1246 participant whom 546 had an established hypertension diagnosis and 699 other had hypertension discovered during study

\section{$>$ Data collection}

Data for demographic and behavioral characteristics were obtained by self-reporting during face-to-face interviews. Demographic variables included items on gender, age, and marital status, level of education, employment status, hypertension duration and average monthly income. The following behavioral variables were obtained by self-reporting: smoking, alcohol use, physical activity, and fruits and vegetables consumption. Smoking and alcohol use were assessed by self-reporting on the use of any tobacco product or alcoholic drink . Participants' levels of physical activity were obtained by self-reported engagement in moderate (yes or no) or vigorous (yes or no) intensity exercise. The questionnaire elicited information on demographic characteristics and health behaviors. The field personnel also took blood pressure and heart rate measurements, and anthropometric measurements (height, weight, and waist circumference). A pilot study was carried out with volunteers from the district of Luzolo in order to assess the tools.

\section{- Measures}

The anthropometric measurements (such as body weight, waist circumference, height) blood pressure, and pulse rate were collected by well-trained Medical students. Blood pressure was measured using digital blood pressure meters (OMRON MIT5 Connect, Kyoto, Japan). The average of the two measures was used in the FINAL analysis.

The size was measured, in a standing position, in a participant without shoes, using a flexible measuring tape (Hemostyl, Sulzbach, Germany).Body weight was also measured with individuals wearing light clothing or standing without shoes using adigital weighing scale (Deluxe GBS-721;Seca Deutschland, Hamburg, Germany). Body mass index (BMI) was computed as weight in kilograms divided by height in meters squared $\left(\mathrm{Kg} / \mathrm{m}^{2}\right)$. A flexible measuring tape was used to measure the size at the level connecting the two iliac crests.

During the survey, questionnaires on eating habits, risky behavior (smoking and smoking, lack of consumption of fruits and vegetables) and physical activities were administered.

\section{$>$ Operational definitions}

Hypertension was defined as a $\mathrm{BP} \geq 140 / 90 \mathrm{~mm} \mathrm{Hg}$ [20] . Diabetes was defined as fasting capillary blood glucose, $110 \mathrm{mg} / \mathrm{dl}$ or history of antidiabetic treatment [21]. Low fruit/vegetable consumption of less than 5 portions of fresh and/or cooked fruits/vegetables a day [22]. Insufficient physical activity was defined as self-reported less than 150 min of moderate intensive activity or less than 75 min vigorous intensive physical activity per week, including walking and cycling [23].

The BMI was further classified into four categories; underweight (BMI <18.5 Kg/m2), normal (BMI 18.5-24.99 $\mathrm{Kg} / \mathrm{m} 2$ ), overweight (BMI $25-29.99 \mathrm{Kg} / \mathrm{m} 2$ ) and obese (BMI $\geq 30 \mathrm{Kg} / \mathrm{m} 2$ [24]. Waist circumference (WC) was used as surrogate for abdominal obesity : > $94 \mathrm{~cm}$ in men and $>80 \mathrm{~cm}$ in women [25]. Cardiometabolic risk (CMR) as the waist-to -height ratio $\geq 0.5$ [26].

Talking alcohol was defined as consumption of more than 1 standard drink (which is the amount of alcohol you find in a small beer, one glass of wine, or one tot of spirits per day for females and more than 2 standard drinks for males [27]. Smoking was defined as the frequent use of 
tobacco in all forms (smoked, prized ) [20]. The socioeconomic level was calculated on the basis of DRC Demographic and Health Survey (DHS) and classified into three degrees : low, middle and high socioeconomic status (SES) [28].

\section{$>$ Data analyses}

Data were analyzed using Statistical Package for the Social Sciences (SPSS) version 21 for Windows (SPSS Inc., Chicago, IL, United States). Data were expressed as mean values \pm standard deviations (SD) for continuous variables. Frequencies (n) and percentages (\%) were reported for categorical variables. Counts (frequency $=n$ ) and percentages (\%) were reported for categorical variables. Percentages were compared using the chi-square test. The logistic regression model analysis adjusted for obesity, physical activity, dietary practices, parity, income and alcohol use. A p-value of $<0.05$.

\section{$>$ Ethical approval}

Obtained from the Ethical Committee of the Ministry of Health ( $\left.{ }^{\circ} 104 / C N E S / B N / P M M F / 2018\right)$. Consent was taken from the subjects who volunteered to participate in the study. Identified hypertensive subjects were referred to the nearby clinic for treatment

\section{RESULTS}

Table 1. General characteristics of the 1245 participants, $455(36.5 \%)$ were males while $790(63.5 \%)$ were females. Their mean age was $47.8 \pm 18.0$ years with $22.9 \%, 22.4 \%, 16.9 \%, 16.5 \%$ and $21.3 \%$ participants aged respectively $<30$ years, 30-39 years, 40-49 years, 5059 years and $\geq 60$ years.

Most participants $(73.6 \%)$ were recruited from the rural suburb; the proportion of unemployed, married, secondary education level and low SES participants was $28.9 \%, 50.5 \%, 53.2 \%$ and $60.6 \%$ respectively. Average levels of SBP, DBP, HR, BMI, WC, and capillary blood glucose were $135.7 \pm 31.0 \mathrm{mmHg}, \quad 87.8 \pm 18.3 \mathrm{mmHg}$, $81.5 \pm 12.2 \mathrm{bpm}, \quad 23.8 \pm 5.2 \mathrm{Kg} / \mathrm{m}^{2}, 84.7 \pm 13.0 \mathrm{~cm}$ and $120.8 \pm 31 . \mathrm{mg} / \mathrm{dl}$, respectively.

Table 2. cardiovascular risk factor profile of th hypertension status physical inactivity $(62.2 \%)$, alcohol intake (46.6\%), Menopause (29.1\%), FH-HT (47.0\%) and obesity $(11.8 \%)$ were cardiovascular risk factors most frequently reported by the participants.

\section{$>$ Prevalence of no awareness of $H B P$}

The no awareness of HBP was observed in 699 (56.1\%) participants (Fig.1), of whom 184 (26.3\%), 394 $(56.4 \%), \quad 338(48.4 \%), \quad 525(75.1 \%), \quad 241(34.5) \quad$ and $438(62.7 \%)$ were person <30 years, women, married, living in rural area, Businessmen and Low SES respectively (Table 1).

Their mean age was $44.7 \pm 17.6$ years and average levels for BMI, SBP, DBP, MAP and PP were 24.1 \pm 6.0 $\mathrm{Kg} / \mathrm{m}^{2}, 139.1 \pm 25.8 \mathrm{mmHg}, 93.1 \pm 15.7 \mathrm{~mm} \mathrm{Hg}, 108.4 \pm 17.4$
$\mathrm{mmHg}, 46.0 \pm 19.3 \mathrm{mmHg}$ respectively. The proportion of unemployed participants and those with secondary education level and low SES was $25 \%, 57.7 \%$ and $62.7 \%$, respectively.

Compared to awareness HBP participants, those with no awareness HBP status were in average significantly older $(42.2 \pm 16.9$ vs $\quad 44.7 \pm 17.6$ years; $p<0.001)$,

Gender [72.5\% ( female) vs $27.5 \%$ (male); $<<0.001$ ], SES [91.8\% (low and middle) vs $8.2 \%$ ( higher ); $\mathrm{p}=0.017$, SBP $\quad(141.7 \pm 20.4$ vs $139.1 \pm 25.8 \mathrm{mmHg} ; \mathrm{p}<0.001)$, DBP ( $97.2 \pm 11.8$ vs $93.1 \pm 15.7, \mathrm{mmHg}$; $\mathrm{p}<0.001$ ), MAP $(112.1 \pm 12.2$ vs $108.4 \pm 17.4 \quad, \quad \mathrm{mmHg}$; $\mathrm{p}<0.001)$, and PP $(44.5 \pm 19.1 \mathrm{vs} \quad 46.0 \pm 19.3 \mathrm{mmHg}$; $\mathrm{p}=0.002)$.

With reference to cardiovascular risk profile (Table 2 ), physical inactivity $(58.9 \%)$, central obesity $(49.6 \%)$, FH-HT (44.1\%), and alcohol intake $(46.4 \%)$ Menopause (23.9\%) were cardiovascular risk factors more frequently observed among hypertensive participants. Compared to awareness HBP participants, no awareness HBP ones had less old than no awareness HBP proportion of older participants (39.0 vs $12.1 \%$; $<<0.001)$, and those with physical inactivity (66.5 vs 58.9\%; p<0.001), FH-HT (41.7 vs $50.7 \%$; $<0.011)$ and menopause $(35.7$ vs $23.9 \%$; $\mathrm{p}<0.001)$.

\section{Treatment and control of hypertension}

Of the 1245 hypertensive patients, 546 (43.9\%) of them were aware of their status of hypertension with a significantly higher proportion of women $(72.51 \%$ vs 56.4 $\% ; \mathrm{p}<0.001)$ (Table 1).

Current pharmacologic antihypertensive treatment was reported by $361(66.1 \%)$ of 546 participants aware of their hypertension status. The antihypertensive regimen was based on 1 and 2 antihypertensive drugs in $263(72.8 \%)$ and $98(27.2 \%)$ treated hypertensive participants $(\mathrm{n}=361)$, respectively; no participant was receiving $\geq 3$ antihypertensive drugs. In those receiving one antihypertensive drug, calcium channel blockers (55.4\%) was the drug class most frequently reported by participants whereas the combination of calcium channel blockers (CCB) and angiotensin converting enzyme inhibitors (ACEIs) $(26.5 \%)$ was most frequently mentioned by those receiving two drugs. BP control was observed in 164 (48.2.8\%) of 188 treated hypertensive participants mainly in men than women ( 78.7 vs $61 \%$; $=0.035)$. Systolicdiastolic uncontrolled hypertension $(67.6 \%)$ was the type most frequently encountered among those with no BP control

\section{$>$ Determinants of awareness $H B P$.}

In univariate analysis (Table 4), cardiovascular risk factors significantly associated with no awareness HBP were Young age $(\mathrm{p}=<0.001)$ and no FH-HT $(\mathrm{p}=<0.001)$. In multivariate analysis (Table 4 ), the associations observed in univariate analysis persisted for young age [a OR 2.00 (1.01-2.83); $\mathrm{p}=0.001)$ ], no FH-HT [a OR 3.42 (1.12-4.79); $\mathrm{p}=0.003$ ] and High SES (a OR 2.41 (1.91-3.69; $\mathrm{p}=0.012$ ]. 


\section{DISCUSSION}

Hypertension is an important cause of death in African countries where the level of screening is still low and therapeutic inertia. The main finding of the study was $56.1 \%$ of prevalence of undiagnosed HTN among study population.

This high prevalence of undiagnosed hypertension is due to several factors, among others: urbanization, change in lifestyle, low level of study, low socio-economic level and not to mention the fact that hypertension is asymptomatic.

Higher prevalence has also been reported in Ghana by Basu et al[30] (83\%) and in DRC by Atoba et al 79.6 $\%[29]$.

Many studies in Africa have reported lower prevalence by Sarra et al (39.6\%\%)[31] Undavalli et al (10.1\%)[32] , Getachew et al, (13.3\%)[33], Gudina et al $(13.2 \%)$, Bonsa et al (16.9\%)[34], Anand et al (26\%) [35]. Men had more undiagnosed hypertension than women (56.4\% vs 43.6) \%), among different types of work, among which we find that those with Businessmen and the unemployed have more undiagnosed blood pressure respectively $34.5 \%$ and $25 \%$. This result corroborates those reported by of Fatiu et al. [36] and Ulasi et al. [37]. It was also higher among the people with a low socioeconomic level $(62.7 \%)$ and Middle socioeconomic level $(26.8 \%)$ quintiles compared to people who belonged to the High socioeconomic level (10.6\%), Married 48.4\%, Female 56.4\% Secondary Education level $55.7 \%$. One interesting finding was that $43.6 \%$ of men and $56.4 \%$ of women diagnosed with HTN were unaware of their condition. This is similar to the result reported in the literature [38, 39]. The difference observed in this study may be due to a lower participation of men, at the low education level and at the low socio-economic level in females.

The study found a higher prevalence of undiagnosed hypertension in participants of secondary education, observation reported by many authors [40, 41].

The proportion of participants aware, treated and controlled was low. This observation corroborates previous studies carried out in cities of the DRC [14,18,42]. Low proportion participants on antihypertensive therapy in the present study is consistent previous studies from DRC and other sub-Saharan African countries [18, 42] that reported values less than $50 \%$ among treated patients. Similar picture has been found for patients who achieved recommended BP goals. The majority of treated participants were receiving monotherapy with mainly calcium channel blockers. The use of a calcium channel blocker or a thiazide diuretic as first line in the treatment of hypertension of blacks, known to have a low plasma renin activity and a subsequent volume-dependent hypertension [43], The majority of treated participants were receiving monotherapy with mainly calcium channel blockers. If the use a calcium channel blocker or a thiazide diuretic as firstline drug in the treatment of hypertension of blacks, known to have a low plasma renin activity and a subsequent volume-dependent hypertension [43].

Young age, no FH-HT and low SES were independent factors associated with undiagnosed hypertension. This finding is consistent with what has been documented by many other studies. [44,45].

Low SES is associated with undiagnosed hypertension. Indeed, the difficulties of implementing screening programs and the lack of access to health care for all, constitutes a major obstacle for the management of HBP [46]. The current study does find a significant association between undiagnosed hypertension and a no family history of hypertension, the lack of association is due to a lack of information [47, 48].

\section{CONCLUSION}

The prevalence of undiagnosed hypertension a is high, a low level of HBP control known in Boma. Hence the need for the implementation of a consistent health policy.

\section{$>$ Author's Contribution}

- BMN designed the project and carried out the investigation

- FLB participated in survey conception and data analysis; revised the manuscript.

- $\mathrm{AN}$ and PKK have conducted data analysis

- BLB, RVV, GLL, and JR M have revised the manuscript.

\section{REFERENCES}

[1]. Mills KT, Bundy JD, Kelly TN, et al. Global disparities of hypertension prevalence and control: a systematic analysis of population-based studies from 90 countries. Circulation. 2016;134:441-50.

[2]. Forouzanfar MH, Liu P, Roth GA, et al. Global burden of hypertension and systolic blood pressure of at least 110 to $115 \mathrm{~mm} \mathrm{hg,} \mathrm{1990-2015.} \mathrm{Jama.}$ 2017;317:165-82.

[3]. Lim SS, Vos T, Flaxman AD, et al. A comparative risk assessment of burden of disease and injury attributable to 67 risk factors and risk factor clusters in 21 regions, 1990-2010: a systematic analysis for the Global Burden of Disease Study 2010. Lancet. 2012;380:2224-2260.

[4]. Twagirumukiza M, De Bacquer D, Kips JG, de Backer G, Stichele RV, Van Bortel LM. Current and projected prevalence of arterial hypertension in subSaharan Africa by sex, age and habitat: an estimate from population studies. J Hypertens. 2011;29:12431252.

[5]. Addo J, Smeeth L, Leon DA. Hypertension in subSaharan Africa: a systematic review. Hypertension. 2007;50:1012-1018. 
[6]. Viera AJ, Cohen LW, Mitchell CM, Sloane PD. High blood pressure knowledge among primary care patients with known hypertension: A North Carolina family medicine research network (NC-FM-RN) study. J Am Board Fam Med. 2008;21:300-308.

[7]. Wofford MR, Minor DS. Hypertension: issues in control and resistance. Curr Hypertens Rep. 2009;11:323-328.

[8]. Odunukan OW, Cha S, Rahman PA, Roellinger D, Nyman MA. Higher mortality in patients with undiagnosed hypertension: is the electronic medical record the key to their identification. Circulation. 2014;130:15348.

[9]. Johnson HM, Thorpe CT, Bartels CM, Schumacher JR, Palta M, Pandhi N, et al. Undiagnosed hypertension among young adults with regular primary care use. J Hypertens. 2014;32:65-74.

[10]. Shukla AN, Madan T, Thakkar BM, Parmar MM, Shah KH. Prevalence and predictors of undiagnosed hypertension in an apparently healthy Western Indian population. Adv Epidemiol. 2015.

[11]. Dolatabadi AA, Motamedi M, Hatamabadi $H$, Alimohammadi H. Prevalence of undiagnosed hypertension in the emergency department. Trauma Mon. 2014;19.

[12]. Atakite F, Erquo S, Kaptoge S, Echouffo-Tcheugui JB, Kengne AP. Burden of undiagnosed hypertension in Sub-Saharan Africa. A systematic review and metaanalysis. Hypertension. 2014;

[13]. Lloyd-Sherlock P, Ebrahim S, Grosskurth H. Is hypertension the new HIV epidemic? Int J Epidemiol. 2014;43:8-10.

[14]. Bayauli MP, M'Buyamba-Kayama JR, Ngoyi NG, Lepira FB, Kayembe KP, Lemogoum D, et al. Trends in prevalence of obesity and hypertension in an urban Congolese community. Journal Epidemiological Research 2018; 4(1): 33-40.

[15]. Blaise Makoso Nimi, François Lepira Bompeka, Aliocha Nkodila, Williams Ilenga, Gédeon LongoLongo, Dieudonné Vangu Ngoma et al. "Prehypertension, Hypertension and Associated Risk Factors among Adults Living in the Port City of Boma in the Democratic Republic of the Congo. A Population-Based Cross-Sectional Survey". Acta Scientific Cancer Biology 4.5 (2020): 24-32

[16]. Kianu B, Mpembele E, Kintoki EV, Makulo JR, Kiazayawoko FZ, Manyebwa JD, et al. Rates of hypertension prevalence, awareness, treatment, and control in Congolese South West Port City.The influence of gender according to groups. Global Journal of Medical Research 2015; 15 (1):1-8.

[17]. M'Buyamba - Kabangu J, Fagard R, Lijnen P, et al. Blood pressure in Bantu of Zaïre: epidemiological aspects. Trop Cardiol 1987; 13(Suppl):S113-20.

[18]. Longo Mbenza B, Efini B, Ekwanzala F, et al. Enquête sur les facteurs de risque des maladies non transmissibles à Kinshasa, capital de RDC selon l'approche steps de l'OMS. Kinshasa 2006.

[19]. Katchunga P, M'Buyamba- Kabangu , Masumbuko B, et al. Hypertension artérielle chez l'adulte congolais du sud Kivu: résultats de l'étude Vitaraa. Presse Med 2011; 40: 315-323.

[20]. Williams B, Mancia G, Spiering W, et al. Guidelines for the management of arterial hypertension. European Heart Journal 2018; 39 (33):3021-104.

[21]. Report of the Expert Committee on the diagnosis and classification of diabetes mellitus. Diabetes Care 2003; 26(Suppl 1): S5-20.13

[22]. Mohsen Gadallah , Soad Abdel , Amira Mohsen and Sahar Kandil. Hypertension and associated cardiovascular risk factors among urban slum dwellers in Egypt: a population-based survey.East Mediterr Health J. 2018;24(5):435-442.

[23]. World Health Organization. "Global Physical Activity Questionnaire (GPAQ)". Geneva, Switzerland.

[24]. World Health Organization (WHO). The problem of overweight and obesity: preventing and managing the global epidemic. Report Series 894; Geneva, WHO, 2000: 537

[25]. Alberti KG, Zimmet P, Shaw. Metabolic syndrome - a new world-wide definition. A Consensus Statement from the International Diabetes Federation. J Diabetes Med 2006; 5(5): 469-480. doi: 10.1111/j.14645491.2006.01858.x

[26]. Browning L, Hsieh S, Ashwell M . A Systematic review of waist-to-height ratio as a screening tool for the prediction of cardiovascular disease and diabetes: 0,5 could be a suitable global boundary value. Nutr Res Rev 2010;23:247-69

[27]. Takeshi K, laria P, Maufroy N, Jean philippe D , Isabelle $\mathrm{M}$ Fakher $\mathrm{N}$, et al. arterial hypertension and arterial pulse. Mt cardio. 2006 ; 2 (5): 493-501.

[28]. Orth SR, Stockmann A, Conradt C, Ritz E, Ferro M, Kreusser W and al. Smoking as a risk factor for endstage renal failure in men with primary renal disease. Kidney Int. 2008; 54: 926-31.

[29]. "2013-2014 Democratic Republic of the Congo Demographic and Health Survey (DHS)". Ministry of Heath and Ministry of Planification, preliminary May (2014).

[30]. Atoba B. C, Kayembe T.C., Batina A S, Mbo M J, Ngandu N L , Tsongo K. Z.,Bolukaoto B. L,et al. Prévalence, connaissance et degré de contrôle de l'hypertension artérielle à Kisangani, RD Congo. KisMed Décembre 2014, Vol 5(2) : 86-93

[31]. Basu S, Millett C. Social epidemiology of hypertension in middle income countries: Determinants of prevalence, diagnosis, treatment, and control in the WHO SAGE study. Hypertension. 2013;62: 18-26.21

[32]. Sarra O. Bushara, Sufian K. Noor, Wadie M. Elmadhoun, Amel A. Sulaiman \&Mohamed H. Ahmed Undiagnosed hypertension in a rural community in Sudan and association with some features of the metabolic syndrome: how serious is the situation? RenalFailure, 37:6, 1022-1026

[33]. Undavalli ,Praveen Madala, Hanumanth Narni. Prevalence of undiagnosed hypertension: a public health challenge. Int J Community Med Public Health. 2018 Apr;5(4):1366-1370 
[34]. Getachew F, Dirar A, Solomon D. Prevalence of Undiagnosed Hypertension and Associated Factors among Residents in Gulele Sub-City, Addis Ababa, Ethiopia. J Community Med Health Educ. 2018;8:590.

[35]. Gudina EK, Yadani M, Sahilu A. Prevalence of hypertension and its risk factors in southwest Ethiopia: A hospital-based cross-sectional survey. Integr Blood Press Control. 2013;6:111-7.

[36]. Bonsa F, Gudina EK, Hajito KW. Prevalence of hypertension and associated factors in Bedele town, southwest Ethiopia. Ethiopian J Health Sci. 2013;24:21-6.

[37]. Anand NS, Tarun M, Bhavesh MT, Meena MP, Komal HS. Prevalence and Predictors of Undiagnosed Hypertension in an Apparently Healthy Western Indian Population. Advan

[38]. Fatiu A, Abubakr S, Muzamil H, Aderoju G, Funmilayo O, Bola $\mathrm{O}$, et al. Undiagnosed hypertension and proteinuria in a market population in Ile-Ife, Nigeria. Arab J Nephrol Transplant. 2011;4:141-146.

[39]. Ulasi II, Ijoma CK, Onwubere BJ, Arodiwe E, Onodugo $\mathrm{O}$, Okafor $\mathrm{C}$. High prevalence and low awareness of hypertension in a market population in Enugu, Nigeria. Int J Hypertens. 2011

[40]. Osman el FM, Suleiman I, Alzubair AG. Clinicoepidemiological features of hypertensive subjects in Kassala town, eastern Sudan. J Family Community Med. 2007;14(2):77-80

[41]. Arslantas D, Ayranci U, UnsalA, Tozun M. Prevalence of hypertension among individuals aged 50 years and over and its impact on health related quality of life in a semi-rural area of western Turkey. Chin Med J (Engl). 2008;121(16):1524-1531.
[42]. Azimi-Nezhad M, Ghayour-Mobarhan M, Esmaeili HA, et al. Newly detected hypertension in an Iranian population: An epidemiological study. Asian Biomed. 2009;3(6):653-662.

[43]. M'Buyamba-Kabangu JR, Anisiuba BC, Ndiaye MB, Lemogoum D, Jacobs L, Ijoma CK, et al. Efficacy of newer versus older antihypertensive drugs in black patients living in sub-Saharan Africa. J Hypertens 2013 ; 27, 729-735.

[44]. Abdelsatir S, Al-Sofi A, Elamin S, Abu-Aisha H. The potential role of nursing students in the implementation of community-based hypertension screening programs in Sudan. Arab J Nephrol Transplant. 2013;6(1):51-54.

[45]. Joshi SR, Saboo B, Vadivale M, et al. Prevalence of diagnosed and undiagnosed diabetes and hypertension in India - Results from the Screening India's Twin Epidemic (SITE) study. Diabetes Technol Ther. 2012;14(1):8-15.

[46]. Basu S, Millett C. Social epidemiology of hypertension in middleincome countries: Determinants of prevalence, diagnosis, treatment, and control in the WHO SAGE study. Hypertension. 2013;62: 18-26.

[47]. Osman el FM, Suleiman I, Alzubair AG. Clinicoepidemiological features of hypertensive subjects in Kassala town, eastern Sudan. J Family Community Med. 2007;14(2):77-80.

[48]. Abdelsatir S, Al-Sofi A, Elamin S, Abu-Aisha H. The potential role of nursing students in the implementation of community-based hypertension screening programs in Sudan. Arab J Nephrol Transplant. 2013;6(1):51-54.

\section{ANNEXES}

\begin{tabular}{|c|c|c|c|c|}
\hline Variables & $\begin{array}{l}\text { Over All } \\
\mathrm{N}=1245 \\
\end{array}$ & $\begin{array}{c}\text { awarness HBP } \\
n=546\end{array}$ & $\begin{array}{c}\text { Undiagnosed HBP } \\
n=699 \\
\end{array}$ & p-value \\
\hline Age, years & $47.8 \pm 18.0$ & $42.2 \pm 16.9$ & $44.7 \pm 17.6$ & $<0.001$ \\
\hline Age categories, n(\%) & & & & $<0.001$ \\
\hline$<30$ years & $285(22.9)$ & $101(18.5)$ & $184(26.3)$ & \\
\hline 30-39 years & $279(22.4)$ & $111(20.3)$ & $168(24.0)$ & \\
\hline $40-49$ years & $211(16.9)$ & $89(16.3)$ & $122(17.5)$ & \\
\hline $50-59$ years & $205(16.5)$ & $92(16.8)$ & $113(16.2)$ & \\
\hline$\geq 60$ years & $265(21.3)$ & $153(28.0)$ & $112(16.0)$ & \\
\hline Gender, $\mathrm{n}(\%)$ & & & & $<0.001$ \\
\hline Female & $790(63.5)$ & $396(72.5)$ & $394(56.4)$ & \\
\hline Male & $455(36.5)$ & $150(27.5)$ & $305(43.6)$ & \\
\hline Residence, $\mathrm{n}(\%)$ & & & & 0.093 \\
\hline Urban & $329(26.4)$ & $155(28.4)$ & $174(24.9)$ & \\
\hline Rural & $916(73.6)$ & 391(71.6) & $525(75.1)$ & \\
\hline Occupation, $\mathrm{n}(\%)$ & & & & 0.004 \\
\hline Senior Staff & $235(18.9)$ & $87(15.9)$ & $148(21.2)$ & \\
\hline Businessmen & $406(32.6)$ & $165(30.2)$ & $241(34.5)$ & \\
\hline Students & $175(14.1)$ & $75(13.7)$ & $100(14.3)$ & \\
\hline
\end{tabular}


ISSN No:-2456-2165

\begin{tabular}{|c|c|c|c|c|}
\hline Public Servants & $69(5.5)$ & $34(6.2)$ & $35(5.0)$ & \\
\hline Unemployed & $360(28.9)$ & $185(33.9)$ & $175(25.0)$ & \\
\hline Marital status, n(\%) & & & & $<0.001$ \\
\hline Married & $629(50.5)$ & 291(53.3) & $338(48.4)$ & \\
\hline Divorced & $48(3.9)$ & $22(4.0)$ & $26(3.7)$ & \\
\hline Widow & 191(15.3) & $103(18.9)$ & $88(12.6)$ & \\
\hline Single & $377(30.3)$ & $130(23.8)$ & $247(35.3)$ & \\
\hline Education level, n(\%) & & & & 0.066 \\
\hline Primary/no & $328(26.3)$ & $161(29.5)$ & $167(23.9)$ & \\
\hline Secondary & $662(53.2)$ & $273(50.0)$ & $389(55.7)$ & \\
\hline University/Superior & $255(20.5)$ & $112(20.5)$ & $143(20.5)$ & \\
\hline $\mathrm{SES}, \mathrm{n}(\%)$ & & & & 0.017 \\
\hline Low & $754(60.6)$ & $316(57.9)$ & $438(62.7)$ & \\
\hline Middle & $372(29.9)$ & 185(33.9) & $187(26.8)$ & \\
\hline High & $119(9.6)$ & $45(8.2)$ & $74(10.6)$ & \\
\hline $\mathrm{BMI}, \mathrm{Kg} / \mathrm{m}^{2}$ & $23.8 \pm 5.2$ & $24.4 \pm 6.5$ & $24.1 \pm 6.0$ & 0.006 \\
\hline $\mathrm{WC}, \mathrm{cm}$ & $84.7 \pm 13.0$ & $85.9 \pm 13.4$ & $85.4 \pm 13.2$ & 0.142 \\
\hline $\mathrm{SBP}, \mathrm{mmHg}$ & $135.7 \pm 31.0$ & $141.7 \pm 20.4$ & $139.1 \pm 25.8$ & $<0.001$ \\
\hline $\mathrm{DBP}, \mathrm{mmHg}$ & $87.8 \pm 18.3$ & $97.2 \pm 11.8$ & $93.1 \pm 15.7$ & $<0.001$ \\
\hline MAP, mmHg & $103.8 \pm 21.5$ & $112.1 \pm 12.2$ & $108.4 \pm 17.4$ & $<0.001$ \\
\hline $\mathrm{PP}, \mathrm{mmHg}$ & $47.9 \pm 19.4$ & $44.5 \pm 19.1$ & $46.0 \pm 19.3$ & 0.002 \\
\hline HR, bpm & $81.5 \pm 12.2$ & $81.6 \pm 12.4$ & $81.6 \pm 12.3$ & 0.890 \\
\hline Blood glucose, mg/dl & $120.8 \pm 31$ & $116.0 \pm 28.2$ & $117.9 \pm 29.7$ & 0.335 \\
\hline
\end{tabular}

Table 1:- General characteristics of the participants accordind to knowledge of the diagnostic of HBP

\begin{tabular}{|c|c|c|c|c|}
\hline Variables & $\begin{array}{l}\text { Over All } \\
n=1245\end{array}$ & $\begin{array}{c}\text { Undiagnosed } \\
\text { HBP } \\
n=699 \\
\end{array}$ & $\begin{array}{c}\text { Awarness HBP } \\
n=546\end{array}$ & p-value \\
\hline Older age*, n(\%) & $486(39.0)$ & $225(32.2)$ & $261(47.8)$ & $<0,001$ \\
\hline FH-HT, n $(\%)$ & $585(47.0)$ & $308(44.1)$ & $277(50.7)$ & 0.011 \\
\hline FH-DM, n(\%) & 132(10.6) & $70(10.0)$ & $62(11.4)$ & 0.251 \\
\hline FH-CVD, n $(\%)$ & $84(6.7)$ & $43(6.2)$ & $41(7.5)$ & 0.202 \\
\hline Smoking, $\mathrm{n}(\%)$ & $234(18.8)$ & $122(17.5)$ & $112(20.5)$ & 0.097 \\
\hline Alcohol intake, $\mathrm{n}(\%)$ & $580(46.6)$ & $324(46.4)$ & $256(46.9)$ & 0.448 \\
\hline Menopause, $\mathrm{n}(\%)$ & $362(29.1)$ & $167(23.9)$ & $195(35.7)$ & $<0.001$ \\
\hline Overweight, $\mathrm{n}(\%)$ & $286(23.0)$ & $157(22.5)$ & $129(23.6)$ & 0.338 \\
\hline Obesity, $\mathrm{n}(\%)$ & $147(11.8)$ & $93(13.3)$ & $54(9.9)$ & 0.038 \\
\hline Central obesity, n(\%) & $617(49.6)$ & $337(48.2)$ & $280(51.3)$ & 0.154 \\
\hline PH-DM, $\mathrm{n}(\%)$ & $107(62.9)$ & $65(67.7)$ & $42(56.8)$ & 0.096 \\
\hline Physical inactivity, n(\%) & $775(62.2)$ & $412(58.9)$ & $363(66.5)$ & 0.004 \\
\hline CMR, $\mathrm{n}(\%)$ & $471(59.5)$ & 419(59.9) & $322(59.0)$ & 0.387 \\
\hline Fruits \& legumes consumption, n(\%) & & & & 0.128 \\
\hline Low & $823(66.1)$ & $472(67.5)$ & $351(64.3)$ & \\
\hline High & $422(33.9)$ & $227(32.5)$ & $195(35.7)$ & \\
\hline
\end{tabular}

Table 2:- Cardiovascular risk factor profile of the the participants 


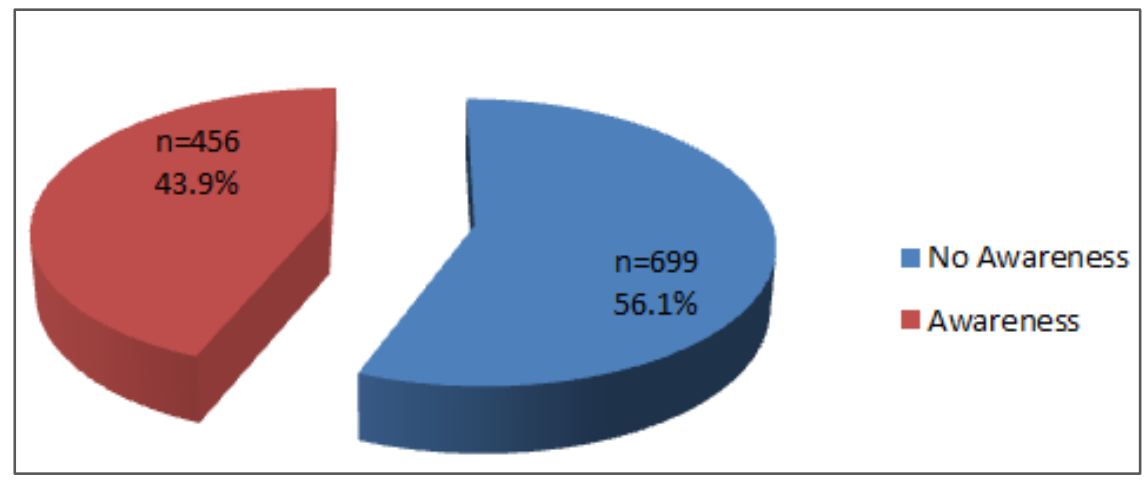

Fig 1:- Prevalence of undiagnosed of HBP

\begin{tabular}{|c|c|c|c|c|c|}
\hline Variable & $\mathbf{N}$ & All & Male & Female & $\mathbf{P}$ \\
\hline Follow up of HBP (years) & & $6,0(5,0-7,0)$ & $5,0(4,0-7,0)$ & $6,5(5,0-10,5)$ & 0,878 \\
\hline Treatment, $\mathrm{n}(\%)$ & 546 & & 150 & 396 & 0.476 \\
\hline No & & 185(33.9) & $50(33.3)$ & $135(34.1)$ & \\
\hline Yes & & $361(66.1)$ & $100(66.7)$ & 261(65.9) & \\
\hline Drug regimen/class & 361 & & 100 & 261 & 0.119 \\
\hline 1 drug, $\mathrm{n}(\%)$ & & $263(72.8)$ & $78(78.0)$ & 185(70.9) & \\
\hline $\mathrm{CCB}$ & & $200(55.4)$ & $54(54.0)$ & $146(55.9)$ & \\
\hline ACEI & & $43(11.9)$ & $17(17.0)$ & $26(10.0)$ & \\
\hline Loop diuretic & & $5(1.4)$ & $2(2.0)$ & $3(1.1)$ & \\
\hline ARA II & & $6(1.7)$ & $1(1.0)$ & $5(1.9)$ & \\
\hline Betablocker & & $5(1.4)$ & $2(2.0)$ & $3(1.1)$ & \\
\hline Thiazide-like & & $4(1.1)$ & $2(2.0)$ & $2(0.8)$ & \\
\hline 2 drugs, $\mathrm{n}(\%)$ & & $98(27.2)$ & $22(22.0)$ & $76(29.1)$ & \\
\hline $\mathrm{CCB}+\mathrm{ACEI}$ & & $96(26.5)$ & $20(20.0)$ & $76(28.7)$ & \\
\hline CCB +Betablocker & & $1(0.3)$ & $1(1.0)$ & $0(0.0)$ & \\
\hline $\mathrm{CCB}+$ Thiazide like & & $1(0.3)$ & $0(0.0)$ & $1(0.4)$ & \\
\hline BP control, $\mathrm{n}(\%)$ & 361 & & 100 & 261 & 0,035 \\
\hline No & & $188(52.1)$ & $61(61.0)$ & $127(78.7)$ & \\
\hline Yes & & $173(47.9)$ & $39(39.0)$ & $134(21.3)$ & \\
\hline No BP control types, $\mathrm{n}(\%)$ & 188 & & 64 & 124 & 0.324 \\
\hline Isolated systolic & & $23(12.2)$ & $8(13.1)$ & $15(13.1)$ & \\
\hline Isolated diastolic & & $38(20.2)$ & $19(26.2)$ & $19(26.2)$ & \\
\hline Systolic/diastolic & & $127(67.6)$ & $37(60.7)$ & $90(70.9)$ & \\
\hline
\end{tabular}

Table 3:- Treatment and control of HBP .

\begin{tabular}{|c|c|c|c|c|}
\hline \multirow[t]{2}{*}{ Variables } & \multicolumn{2}{|c|}{ Univariate } & \multicolumn{2}{|c|}{ Multivariate } \\
\hline & $\mathrm{p}$ & $\mathrm{aOR}(95 \% \mathrm{CI})$ & $\mathrm{p}$ & $\mathrm{aOR}(95 \% \mathrm{CI})$ \\
\hline \multicolumn{5}{|c|}{ Young age, yrs } \\
\hline No & & 1 & & 1 \\
\hline Yes & $<0.001$ & $1.93(1.53-2.43)$ & 0.001 & $1.92(1.01-2.83)$ \\
\hline \multicolumn{5}{|l|}{ FH-HT } \\
\hline Yes & & 1 & & 1 \\
\hline No & $<0.001$ & $3.31(1.04-5.64)$ & 0.003 & $3.42(1.12-4.79)$ \\
\hline \multicolumn{5}{|l|}{ SES } \\
\hline High & & 1 & & 1 \\
\hline Middle & 0.400 & $1.19(0.79-1.79)$ & 0.520 & $1.14(0.76-1.71)$ \\
\hline Low & 0.024 & $2.63(1.07-3.48)$ & 0.012 & $2.41(1.91-3.69)$ \\
\hline \multicolumn{5}{|c|}{ Menopause } \\
\hline Yes & & 1 & & 1 \\
\hline No & 0.019 & $1.77(1.38-2.27)$ & 0.872 & $1.34(0.69-1.56)$ \\
\hline \multicolumn{5}{|c|}{ Physical activity } \\
\hline No & & 1 & & 1 \\
\hline Yes & 0.007 & $1.82(1.10-2.74)$ & 0.085 & $1.23(0.97-1.57)$ \\
\hline
\end{tabular}

Table 4:- Determinants of undiagnosed HBP in logistic regression analysis. 